\title{
PREPARING FOR THE COMPLEXITIES OF TEACHING: MODELING CONCEPTUAL THINKING IN POST-OBSERVATION CONFERENCES
}

\author{
Jane K. Harvey \\ University of South Florida \\ Tampa, FL, USA \\ Camilla Vásquez ${ }^{* *}$ \\ University of South Florida \\ Tampa, FL, USA
}

\begin{abstract}
In order for teacher educators to prepare teachers for complexities of language teaching, their nature needs to be understood. Vygotskian sociocultural theory offers a useful framework for construing such complexities. Vygotsky distinguished between everyday and scientific concepts, and saw the interaction of the two as conceptual thinking, the basis for higher order cognitive skills. Johnson (2009) frames learning to teach as the development of conceptual thinking and considers the nature of the dialogue in teacher education activities as crucial to this development. Drawing on longitudinal data from a semester-long case study of the dialogic interactions between a teacher and teacher educator, this study illustrates how the teacher educator modeled conceptual thinking in her language. We propose a taxonomy of conceptualizations about language teaching that may help teacher educators be more purposeful in designing activities for and interacting with novice teachers.
\end{abstract}

Keywords: sociocultural theory, conceptual thinking, post-observation conferences.

\section{Preparing For the Complexities of Teaching: Modeling Conceptual Thinking in Post- Observation Conferences}

As the title of this issue suggests, teaching is a complex activity, and second language teaching has been considered as yet especially complex. Drawing on Schulman's concept of pedagogical content knowledge, developed in relation to general teacher knowledge, Freeman (2002) argues that pedagogical content knowledge becomes "a messy and possibly unworkable concept" (p. 6) when applied to language as subjectmatter. Similarly Borg (2006) has identified what differentiates language teaching from the teaching of other subjects: that is, the subject matter-language-the range of materials, methods, and activities available to language teachers, and the especially close relationships between language teachers and learners, among other issues. With language as both medium and content of instruction, the teaching of language becomes distinct from the teaching of other content areas.

Not only is language teaching complex, but, as Johnson and Golombek (2011) point out, teacher professional development is "a complicated, prolonged, highly situated, and deeply personal process that has no start or end point" (p. xi). As Johnson (2009) claims, Vygotskian sociocultural theory offers a lens through which the complexities of both language teaching and language teacher learning can be analyzed and observed. Vygotsky distinguished between two basic types of

\footnotetext{
* Jane Harvey has been an English language teacher and teacher educator for over thirty years in the UK, Turkey, Italy, and the USA. She received her Ph.D. in Second Language Acquisition from the University of South Florida, where she works as an ESL program coordinator. Her research interests include the application of sociocultural theory to language and language teacher education. Email:jkharvey@usf.edu

${ }^{* *}$ Camilla Vásquez is an Associate Professor of Applied Linguistics in the department of World Languages at the University of South Florida. Her discourse analytic research examines interactions from many different contexts, including those of language teacher education and mentoring. E-mail: cvasquez@usf.edu
} 
concepts - spontaneous or everyday concepts, ${ }^{1}$ and scientific concepts. Everyday concepts are developed during day-to-day lived experience whereas scientific concepts are "taught" most often during formal schooling. As Vygotsky explained, "the inception of a spontaneous concept can usually be traced to a face-toface meeting with a concrete situation, while a scientific concept involves from the first a 'mediated' attitude towards its object" (1986, pp. 193-194). In other words, and to take the context of language teaching as an example, any individual would acquire everyday concepts about classroom procedures, the kinds of mistakes students make, and so forth, simply from experience in the language classroom. However, the understanding of language pedagogy, or the scientific concepts, would need to come from formal input, be it in a class context, or through reading, for example.

Whereas spontaneous concepts are unsystematic because they emerge spontaneously, scientific concepts form a coherent, logical, hierarchical system (Daniels, 2007), and therefore engender more systematic and logical thinking in the individual. Scientific concepts are abstractions whereas spontaneous concepts are highly contextualized in lived experience. As Wertsch explained, "in spontaneous concepts the [individual's] attention is always centered on the object being represented, and not on the act of thought that grasps it" (1985, p. 103). This abstraction allows the learner to transcend the physical, visual situation of a particular context, and apply the concept to other situations and contexts (Gredler \& Shields, 2008). Table 1 offers a summary of the essential differences between spontaneous and scientific concepts.

Table 1

Spontaneous Versus Scientific Concepts

\begin{tabular}{l|l}
\hline Spontaneous concepts & Scientific concepts \\
\hline $\begin{array}{l}\text { originate in lived } \\
\text { experience }\end{array}$ & originate in formal \\
instruction \\
immediate & mediated \\
unsystematic, not tied to & part of a systematic, logical \\
other concepts & hierarchy of concepts \\
highly contextual & abstractions, decontextualized \\
not open to inspection & open to inspection \\
\hline
\end{tabular}

Despite this distinction that Vygotsky drew between spontaneous and scientific concepts, he saw their interaction and interdependence as a prerequisite for the development of higher order thinking skills. Scientific concepts are verbal abstractions, embedded in theory and closely related to other abstract concepts. However, their integration within a system of knowledge with everyday concepts facilitates understanding of phenomena in their particularity (Bakhurst, 2007). This interdependent relationship is the key to understanding the mastery of conceptual thinking. While scientific concepts remain abstractions, decontextualized from lived reality, they exist only as word meanings. However, when they are integrated with spontaneous concepts, they allow the learner to understand and explain the lived experiences of those spontaneous concepts, "to carry out mental activity that is maximally independent of the concrete context" (Wertsch, 1985, p. 104). Thus, thinking in concepts, resulting from this interweaving of spontaneous and scientific concepts, "leads to the discovery of the deep connections that lie at the base of reality, to recognizing patterns that control reality, to ordering the perceived world with the help of logical relationships cast upon it" (Vygotsky, 1930-1931/1998b, p. 48, cited in Gredler, 2009, p. 7).

Recent research into language teacher learning conducted within an SCT framework demonstrates how learning to teach involves learning to think conceptually about teaching. For example, Johnson (2009) demonstrates how a language teacher's narrative traces the development of her ability to think conceptually about the constructs of subjectivity and subject positioning in light of a reading on social identity, investment, and second language learning as she reflected on her classroom practice with a 15-yearold ESL student. Johnson shows how through this teacher's application of the theoretical constructs to make sense of her lived experiences in the classroom "she uses the discourse of theory (scientific concepts) to rethink, re-organize, and rename her experiences... Thus the theoretical constructs articulated in Norton's [1995] article function as psychological tools (scientific concepts) that mediate her thinking in ways that lead to new ways of thinking about L2 teaching and learning" 
(p.32). Here then, Johnson reports on how the interplay of lived experience and theoretical knowledge influenced the development of a teacher's thinking.

In another study, Dunn (2011) traces the development of conceptual thinking about social inclusion in students enrolled in a second language teacher education methods course. He illustrates the development from the initial imitation of the (scientific) concepts presented with connections made to student teachers' prior knowledge (everyday concepts), through a more sophisticated understanding of the concepts to the stage where they could envision alternative practices informed by the theoretical concepts. In a similar study, Nauman (2011) found that the interplay between a Chinese teacher of English's existing knowledge, her lived experience in the classroom, and the scientific concepts she was being introduced to, helped her create new classroom practices and exploit the conceptual tools to produce new materials. Nauman stresses the importance of the teacher's classroom as an important site for learning, allowing her to "link the scientific concepts with her everyday concepts and experiences, resulting in the emergence of a true concept" (p.116). She notes also how this concept development was mediated by the teacher's interaction with the author and by the responses of her students to what she was doing.

This mediation through dialogue has been seen to play a pivotal role in the development of teacher expertise. Several studies have explored the role of dialogue in teacher development and others have focused on the nature of the dialogue. Examining the role of language in language teacher development, Freeman (1991) investigated how four student teachers' learning was reflected in their language use during an 18-month inservice language teacher education program. His study suggested that participating in the discourse shared by a professional community (and thus being able to express their thinking with that community and others), enabled the teachers to develop their conceptions of teaching. They developed the ability to use forethought and planning, and afterthought in analysis and reflection, enabling them to separate themselves from their actions. This clearly echoes the Vygotskian idea of gaining control over higher mental functions through the development of conceptual thinking by means of the interplay of spontaneous concepts (gained through lived, practical experience in the classroom) and scientific concepts (gained through formal instruction and symbolized through the professional discourse of language teaching).

From an SCT perspective, the role of conceptual thinking in learning to teach cannot be underestimated. As Johnson (2009) explains, "conceptual thinking serves as the basis for expertise in any professional domain. Teachers demonstrate their expertise by thinking in scientific concepts, not just holding them" (p. 64). She goes on to assert that "the activities of L2 teacher education must assist teachers in this process of making their everyday concepts explicit, of reflecting on and critiquing them, and of beginning to think in concepts about aspects of their teaching which are relevant to their daily professional lives" (pp. 64-65).

Although she does not adopt an SCT framework, Tsui's (2003) work on teaching expertise sees an important role for the parallel development of professional discourse and understanding of teaching. Like Freeman (1991, 1993) and Shulman (1988), Tsui conceives of the role of professional discourse in teacher learning as a process of making tacit knowledge explicit. She explains that teachers' 'informal knowledge [is] largely dormant or tacit in most teachers, and they often have difficulties articulating it or making it explicit when asked" (p. 353). This notion of tacit knowledge is reformulated by SCT theorists as spontaneous concepts-that is, concepts and ideas gained through lived experience but not available for scrutiny or analysis, and not under the mental control of the individual. By offering names and definitions for these spontaneous concepts, and by encouraging their use in professional discourse, "experts" such as teacher education faculty or mentors can assist teachers in gaining mental control over those spontaneous concepts by helping them abstract and decontextualize their lived experience and therefore apply their understanding to new situations (Smagorinsky, Cook, \& Johnson, 2003), thus fostering the development of conceptual thinking and impacting their subsequent classroom practice.

Expertise in teaching is, therefore, seen as the ability to think conceptually about teaching, which is both 
reflected in and fostered by the language used to talk about teaching. Given that dialoguing about teaching plays such a crucial role in teacher education activities, understanding how conceptual thinking is reflected in the discourse of that dialoguing would enable teacher educators to be more purposeful in the way they orchestrate dialogue with novice and student teachers. However, very little research has been conducted into exactly how discourse about teaching between teachers and teacher educators actually functions to support this development of conceptual thinking. The goal of this paper is to present evidence of how a teacher educator modeled conceptual thinking in her discourse during a series of post-observation conferences (POCs) with novice language teachers. In particular, the results of the study exposed the unique characteristics and intentionality of the mentor's modeling of conceptual thinking. There is no doubt that there exists the potential for this modeling to open up a social space for the novice teacher to engage in conceptual thinking. However, in this paper we are focusing solely on the modeling function of the mentor's language. ${ }^{2}$

In contrast to traditional notions of supervisory observations, the intent of the POCs conducted as part of this study was to help the teachers improve their understanding and control of classroom teaching; in other words, there was an overt teaching rather than evaluative function to these observations. ${ }^{3}$ As such, these POCs offer the perfect site to investigate how language reflects and informs conceptual thinking about teaching for several reasons. The primary instructional means within them was dialogue between the mentor and teacher. The focus of the interaction was the retrospective analysis of a lesson and thus was highly conducive to the conceptual and verbal linking of lived experience (everyday concepts) with formal knowledge (scientific concepts). However, the POCs also had a more prospective, future-orientated focus of helping the teacher be more purposeful in planning future classroom activities. Similarly, these POCs were approached by both teacher and mentor as a teaching/ learning opportunity, and as such the roles of expert and novice were salient.

\section{The study}

The study was conducted in a large university intensive English program and involved the participation of a mentor (first author) and two novice ESL teachers. The mentor observed the teachers teach for a total of five times each over the period of one semester. One teacher, Rick (pseudonym), was a native English speaker and in his second semester of ESL teaching, having recently completed his MA in Applied Linguistics. The mentor observed him in an intermediate level grammar class. The other teacher, Pepa (pseudonym) was a native Spanish speaker who had taught EFL in Spain and was in her first semester of teaching after earning an MA in Applied Linguistics. The mentor observed her teach an advanced level business topics class. Post-observation conferences (POCs) were held after each observation. Each of these discussions was recorded and later transcribed.

These data were analyzed using an approach based on Mercer's (2004) sociocultural discourse analysis, whose major tenets include a focus on the function of language, specifically dialogue for the pursuit of joint intellectual activity, and the use of selected extracts of transcribed talk commented on by the analyst. Through iterative readings of the data, instances of the mentor's discourse where conceptual thinking was in evidence were identified and agreed upon during discussions between the two authors. For a more detailed account of the data analysis procedures, see Harvey (2011).

\section{Analysis}

Many examples of the modeling of conceptual thinking in the mentor's discourse were identified in the data. Categories of conceptualization emerged inductively through both iterative readings of the data and discussions, and these categories reflected levels of abstraction from lived experience and generalizations across contexts. The categories identified were Ideation, Analytic ideation, Terminizing, Generalizations, and Principles. As shown in Figure 1, these levels could be deemed to represent levels of decontextualization and abstraction, from ideation of lived experience to the level 
of generalizations and principles across many contexts. How each of these levels occurred in the language of the mentor will be shown in the following sections.

\begin{tabular}{l}
\hline Principles \\
Generalizations \\
Terminizing \\
Analytic ideation \\
Ideation
\end{tabular}

Figure 1. Taxonomy of conceptualization

\section{Ideation}

This term is used to mean the encapsulation into verbal form of the concept or idea behind a single and context-bound lived experience. There are several examples in the data where the mentor "ideated" a teaching strategy in her discourse. This could be related to the materials the teacher was using, as in Extract 1, or to a specific teaching strategy, as in Extract 2.

\section{Extract 1}

$\mathrm{J}$ : part B yeah you might you might I mean this is- this is one of these activities where it's kind of like a test a little bit like these Holes materials if they know it they can do it if they don't know it they can't

Here the mentor's words, kind of like a test, ideated a feature of the materials under focus in a way that abstracted out from the materials themselves, and modeled cognition on a more conceptual level. Similarly, in Extract 2, the mentor's response demonstrates a higher more abstract level in reaction to a narrative told by Pepa, the teacher. Whereas the teacher's talk reported on a conversation with a student that the mentor had not witnessed (i.e., what Pepa had said and what the student had said), the mentor's reframing of that specific incident to a more general level explaining the rationale moves the dialogue from reporting of lived experience to a more abstracted conceptual level.

\section{Extract 2}

P: yeah and then this student came to me and he's like "oh you know I work better alone that's in Spanish because it takes me a long time to translate everything and then if I sit with someone they always know more than me and then they give me all the answers and then I don't work" I'm like "precisely what you have to do when you sit with someone like that that knows more than you is to ask them what they think and then maybe you say 'ok stop' say first 'what does it mean' and then ask him what he means because by him telling you he's learning it and then you're learning it from him and not from me because I don't have all the right answers ( $\mathrm{J}$ : or the time) or the time right" so you know he was like "I don't want to work with anybody" and now you know he does (J: he now he's convinced) yeah yes and I was trying you know (J: how cool is that) yeah and it was like after class I spent with him ten minutes knowing about cooperative learning- language learning [laughs] and [unclear] and he was like "oh" ok cos he's science his education comes from a science background so

J: right but you know sometimes explaining the rationale $(\mathrm{P}: \mathrm{mhm})$ great instinct to do that cos it convinces them like instead of just with this class [...] um yeah instead of saying to them you know you could have just started with the vocabulary and then done the reading but you explained to them the rationale and they're on board far more with it

Whereas Pepa's narrative reported an unwitnessed event, the mentor's language functioned on the level of abstraction and concept formation, thus modeling a more decontextualized way of conceptualizing the lived experience.

Extract 3 shows another instance of where the mentor's ideation through language modeled the kind of conceptual thinking she was looking to encourage in the teachers. 


\section{Extract 3}

$\mathrm{J}$ : and the design of the task was phenomenal because it would have been very easy to just give them that and just ok take notes but actually giving them the paper (P: right) a masterstroke there it is there- it's this- it's this defined manageable achievable task (P: $\mathrm{mhm}$ ) "take notes" it's unending you have a small box (P: $\mathrm{mhm}$ ) "I can fill that small box with big writing and then I'm successful" or with small writing you know (P: mhm) it's it's yeah so I think- I think that that's you know good stuff

This extract shows where the mentor ideated the qualities and features of an activity that Pepa had devised for her students in the words it's this defined manageable achievable task. Task design was a topic that arose consistently throughout the POCs with Pepa, and thus on this occasion, the mentor was able to model a generalized conceptualization on the topic of task design through her decontextualized language.

In a similar way, Extract 4 also shows an occasion where the mentor focused the ideation on a single teaching strategy. In this discussion about Pepa's decision to spend more time than planned on a specific activity in class, the mentor used the opportunity to model a more decontextualized abstract conceptualization.

\section{Extract 4}

$\mathrm{J}$ no I don't think in any way that you spent too long on that I think that was a great decision I think you know it's so worthy of you that you didn't think "oh my god" you know "I need to get through my materials" you were focused- you were student orientated you knew what was right for them and giving them the- this was [nodding head]

Here the words you were student orientated encapsulated the reason why it was a pedagogically sound decision to allow students more time to work on the activity from a more decontextualized and abstract perspective. Once again, the mentor was able to reconceptualize the specific incident of lived experience to a more abstract decontextualized level.

The examples of ideation discussed above show an aspect of the mediation where, through her language, the mentor modeled conceptual thinking about the specific lived events of the classroom in order to promote a more abstract and decontextualized understanding of how and why events occurred and perhaps should occur.

\section{Analytic ideation}

We use the term analytic ideation to refer to instances in the discourse where the mentor ideated aspects of the teachers' lived experience of the classroom through conceptualizations of their types or parts. In other words, the mentor modeled a type of conceptual thinking in which a lived experience was opened up for examination through conceptual analysis. The first example (Extract 5) shows how the mentor used analytic ideation to praise a classroom activity by conceptualizing its parts. During the second observation lesson conducted with Rick, he gave the students a quiz that he had prepared himself.

\section{Extract 5}

J: I know because my- you know when I looked at this I thought ok that you know first it's totally recognition right where they have to produce no language the secondly they've got most of the language and they have- just have to change it a bit (R: right) the third one they got the topic and then they haveand then they have to produce language and the fourth one is completely free so I'm thinking that is great sequencing you know from totally receptive to totally productive

Here the mentor identified the structure of the quiz, ideating what students had to do in each section in turn (they have to produce no language ... they've got most of the language and they...just have to change it a bit...they got the topic... and they have to produce language...completely free) and then offer an ideation of the progression as a whole: totally receptive to totally 
productive. This modeled a conceptualization of the lived experience of the quiz that related it to the scientific concepts of test design. Elsewhere and talking about the same quiz, the mentor ideated analytically with regard to the results of the same quiz and the possible cause of student problems with it (Extract 6).

\section{Extract 6}

$\mathrm{J}$ : right so- so a-s if those students and it sounds like a lot of them couldn't do this first task but could do the rest that tells you that they can use the language but that maybe the task here wasn't clear

Here the mentor differentiated between problems caused by the quiz task and problems caused by possible lack of language knowledge (that tells you that they can use the language but that maybe the task here wasn't clear). Again this analytic conceptualization of the parts of the lived experience and concrete material of the quiz was modeling a way of conceptualization of teaching at a higher cognitive level.

Another focus for analytic ideation was the actual teaching strategies the mentor witnessed during the observed lessons. Extract 7 shows an occasion where the mentor focused on the different strategies for dealing with student error in one of Rick's lessons.

\section{Extract 7}

J: yeah and you put that on the board she said "shoes is" and everybody went "shoes are" yeah and so there are two very different things one was that very implicit you know you did the recast correction and the other one was the very explicit you know nothing wrong with doing them but just thinking about "why am I doing this now which is the- how can I_ yeah which is the most appropriate" who knows

In the early stages of the lesson a student had replied sleep to Rick's question about what the students had done over the weekend. Rick's response was to say, ah you slept. Later, when a student made a similar grammatical error, Rick put the erroneous utterance on the board and asked the class to correct it. In the post-observation discussion, the mentor ideated these different types of error correction strategy using the words implicit and explicit. In all these instances, the mentor modeled the conceptualization of events in a way that was more abstract than a narrative restricted in focus to only one specific incident of lived experience, thus modeling the type of decontextualized and more generalized cognizing, and the thinking in concepts associated with teacher learning (Johnson,2009).

\section{Terminizing}

On several occasions, the mentor achieved the ideation of an aspect of the teaching observed or of the post-observation discussion through an articulation of an accepted term for the phenomenon, part of what Freeman (1991) called the discourse of language teaching. We called this reframing by the mentor terminizing. On several occasions the mentor offered a metalinguistic term in response to Rick's mentioning of specific language features. In Extract 8, the mentor used the term perfect infinitive as an ideation of the form would have done something mentioned by Rick.

\section{Extract 8}

P: $\quad$ so then I was like "so how would we say if I had this yesterday I would have you know I would have done something yesterday" so I was like "we use the present perfect"

J: it's actually a perfect infinitive ...would with perfect infinitive you know

In Extract 9, the mentor ideated the specific sentence offered by Rick as an example of the first conditional or the real conditional.

\section{Extract 9}

R: there were five uh different ones so like it's A were all you know if you see Tom tell him I have his keys something like that 
$\mathrm{J}$ : right what they call the first conditional the real conditional yeah

On other occasions, the mentor ideated using not metalinguistic but pedagogical metalanguage, as exemplified in Extract 10, with the term information gap, and 11 with the term form focused controlled practice.

\section{Extract 10}

P: I'm going to pair them uh I'm going to try to pair them in different in different countries

$\mathrm{J}$ : $\quad$ so they'll- so there'll be an information gap

\section{Extract 11}

R: we'll probably talk about that in class and then I have some um a bunch of sentences and stuff and choosing and removing

$\mathrm{J}$ : so really form focused controlled practice which they need

On another occasion, the mentor attempted to make an ideational connection between the lived experience of the quiz that Rick had created and the scientific concepts of reliability and validity (Extract 12).

\section{Extract 12}

$\mathrm{J}$ : but that says a lot your test then the- what is it the validity the reliability I don't know um that it actually tested what you wanted it to test (R: $\mathrm{mhm}$ ) and it reflected you know students' ability (R: yeah) great

However, the mentor's own lack of confidence in her mastery of the concepts behind the terms validity and reliability led her to ideate through less specific language - it actually tested what you wanted it to test [...] and it reflected you know students' ability". Here, not only was the mentor encouraging the teacher to conceptualize the lived experience on a more abstract decontextualized level, but she was also making a reference to the lexicon of the wider professional discourse community. She stimulated the teacher to connect the lived experience with the abstract generalization, or scientific concept, that had been presented in the content courses of the teachers' Master's program.

In all of the instances above, the mediational discourse involved the ideation of some aspect of the teacher's lived teaching experience-that is, moving from concrete experience to a more abstract, decontextualized plane. The following three types of conceptualization that emerged from the data represent different and progressively more abstract-in the sense of decontextualized-levels of cognition.

\section{Generalizing}

Another feature of the mentor's modeling of conceptual thinking was to abstract out from the event or feature of the lived experience under focus to make a generalization. This type of conceptual thinking demonstrated how through an ability to abstract out from one specific context and generalize to others, the teacher can understand and anticipate more accurately during her lessons, with a view to better being able to manage and preempt classroom issues. This demonstrates the retrospective and prospective functions of conceptual thinking. There were two main areas focused on by the mentor's modeling of conceptual thinking through generalizations: managing student learning and classroom management.

One generalization about student learning that recurs several times in the data was the idea that the teacher can only be sure of what a student knows or thinks when she or he hears the student talk, an ideation that occurred frequently in the discussions with Pepa. In other words, just because the teacher explains something, there is no guarantee that the students actually understand the explanation. Extracts 13 and 14 present two examples of this. In extract 13, the mentor was asking Pepa to reflect on whether students had understood her explanation of the word deportment. She mentioned that she had given her own example but had not given the students an opportunity to give their own examples. 


\section{Extract 13}

J: right because we don't know- you know as always you know what I'm- what I say that when we're talking we've no idea what they're understanding but when they're talking we have an idea about what's going on

Here the mentor stated the generalization about the need for students to be able to offer examples and explanations as a way for the teacher to check their understanding. In extract 14 taken from a later POC, Pepa was describing an instance where she had been able to check students' understanding by asking them for a definition, rather than giving it herself.

\section{Extract 14}

$\mathrm{J}: \quad$ right and also when they say it we know that they're thinking it when we say and explain we've no idea of what's going on, what they're hearing

Again the mentor reiterated the generalization behind the value of comprehension checks (when they say it we know that they're thinking it).

A scientific concept behind the idea of students' understanding being reflected in their discourse is the Vygotskian concept of internalization. However, the mentor was not able to use this scientific concept in the POC discussions with Pepa as she was not familiar enough with the concept to be able to relate it to her lived experience in a way that would have facilitated her understanding and conceptual thinking about the lived experience. The mentor therefore framed the concept as an explanation (when we're talking we've no idea what they're understanding but when they're talking we have an idea about what's going on) rather than using the scientific term.

On another occasion, the mentor was able to use a scientific concept to encourage Pepa to conceptualize more generally from her lived experience. Pepa had been complaining that in her tutoring sessions students were focused almost exclusively on the standardized university entrance exams, such as the GMAT and
GRE. From her comments, the mentor generalized out to conceptualize students as product as opposed to process orientated (Extract 15).

\section{Extract 15}

P: you know it's so good for them to rewrite things and they just don't show up I don't get anybody in the tutoring center I don't get anybody and if I do it's for freaking TOEFL or the GMAT or the GRE that's all they care about ahhh

J: yeah they're product orientated aren't they not process

Similarly, when Rick had described what he considered to be a successful activity because of the way the students engaged with it, the mentor made the generalization that it was the intellectual challenge (Extract 16) of the activity to which students responded because it made them feel as if they were learning.

\section{Extract 16}

R: some of them kind of whipped got though it really quickly and then they went back and they were thinking and asking questions about it and I could see that they were all working on it and talking about it so

J: $\quad$ mhm yeah they did they rea- that's why I said at the end of the lesson remember you said you know do a game so- they find this kind of think very satisfying I think they like the intellectual challenge of that they- and when they have to think about something they feel they're learning

Other generalizations focused on the nature of students and the teacher's behavior as influences on classroom management. In Extract 17, the mentor generalized from the discussion about how Pepa could respond to the negative behavior from two of her students.

\section{Extract 17}

$\mathrm{J}$ : right $\mathrm{I}$ think right there's a danger of being too patient and there's a danger of being personally 
confrontational you know "don't do that because I'm telling you not to" that's never going to work with them their personalities are much stronger than ours they're men and they've been brought up to be the center of the universe

Here the mentor conceptualized the dilemma of the teacher on a very generalized level - as a dichotomy between being too patient and being confrontational. She then conceptualized the behavior of the two students as a type, indeed more as a stereotype: their personalities are much stronger than ours they're men and they've been brought up to be the center of the universe. On another occasion, the mentor generalized about the personality of the teacher himself, and how that might affect classroom management (Extract 18).

\section{Extract 18}

$\mathrm{J}$ : yeah and it seems to me that your personality is very laissez faire ( $\mathrm{R}$ : $\mathrm{mhm}$ ) right you know it's very much not a control freak like I am in the classroom um and which is great and there's absolutely nothing wrong with that at all but it's like when they you know when they- it all gets a little bit out of hand it's hard for you to step in and be tight

The discussion had been focusing on Rick's issues with classroom management, and keeping control of overly talkative and potentially disruptive students. By generalizing about Rick's personality (very laissez faire), the mentor was able to suggest a reason why Rick was having the classroom management problems (it's hard for you to step in and be tight), thus again modeling the decontextualized conceptual thinking that allows the teacher to understand, explain and ultimately control and regulate the lived experience of the classroom beyond the specific lived experience under focus. Generalizations in the mediational discourse functioned as a way to model thinking in concepts of the teacher's lived experience. According to sociocultural theory, when internalized by the teacher, this would allow more mental control over the teacher's reactions in the future and therefore more purposeful classroom decisions.

\section{Principles}

Whereas generalizations serve to retrospectively conceptualize aspects of lived experience in a more decontextualized and abstract way, principles serve a more future-orientated function. Principles constitute a pivotal point between retrospective reflection on and reconceptualization of lived experience and more prospective planning for and regulating future behavior. Given the teaching function of the POCs of this study, it is not surprising that there were many instances in the data where the mentor modeled thinking in concepts by articulating a principle as a basis for decisions about future classroom practice. Extracts 19 and 20 present two examples of the mentor's articulating principles. In extract 19, the mentor was discussing with Pepa an instance where two students had not participated fully in the activity which had led her to tell them either to participate or just sit and not disturb other students. The mentor endeavored to offer a middle way.

\section{Extract 19}

J: right now I'm thinking about scaffolding participation [...] I wonder if there's a- again in what way can one encourage participation make them want to participate

The mentor offered the principle of scaffolding participation as a way of encouraging students to become more involved in activities. In extract 20, the mentor was discussing with Rick the need to encourage students to focus on accuracy during the grammar class he was teaching

\section{Extract 20}

J: and maybe that's something that you could do you could take a more maybe purposeful approach to monitoring them when they're doing a discussion like this

Here, she suggested the principle of taking a more proactive approach to student errors by taking a more 
purposeful approach to monitoring in order to encourage students to attend to the quality of their language.

In the extracts above, the mentor's language modeled the type of thinking in concepts that experienced and expert teachers are able to perform when reflecting on, planning and conducting their classroom teaching.

\section{Discussion}

As mentioned previously, promoting conceptual thinking about teaching in novice teachers is a central aim of second language teacher education activities and this study has demonstrated how exactly the modeling of conceptual thinking was achieved during the interaction between mentor and teacher in POCs. This involved different types of conceptualizations: ideation (encapsulating into verbal form and abstracting out from lived experience), analytic ideation (lived experience opened up for examination through conceptual analysis of its types or parts), terminizing (ideation through the use of a decontextualized general and accepted term, offering a link with the wider discourse community), generalizing (abstracting out from the lived experience to a generalizable conceptualization), and principles (representing a pivotal conceptualization between retrospective generalizations and prospective principles for future practice).

In terms of its function within conceptual thinking as reflected in the data, this taxonomy could be represented by a diagram such as Figure 2. Here there is a horizontal continuum which runs from the very contextualized nature of lived experience (ideation of lived experience) to the very decontextualized nature of generalizations and principles. Through language, we conceptualize the objective activity that is our lived experience by means of one or more of the different levels of conceptualization found in the data-that is, ideation, analytic ideation, terminizing, generalizations, and principles-and then re-concretize that conceptualization again to inform, envision, and plan objective activity-this time, future practice.

contextualized $\longleftrightarrow$ decontextualized

classroom activity
(lived experience)

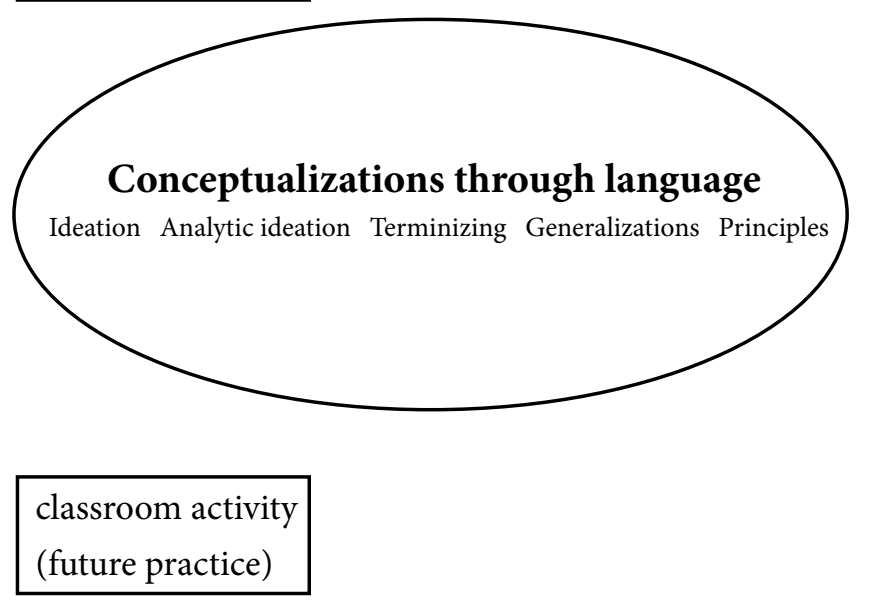

Figure 2. The function of conceptualizations within conceptual thinking

It is beyond the scope of this paper to examine how far the teachers developed the ability to think conceptually about the topics under discussion as a result of the interaction with the mentor; future examination of the data could undertake this. However, awareness of how conceptual thinking is represented in dialogues about teaching can help teacher educators to be more aware of their own language and to be more purposeful in their attempts to promote conceptual thinking in the teachers with whom they work. The implications of this for teacher education in general and the conduct of POCs in particular are to underscore the value of the conscious leading of teachers' focus out from the retrospective and contextualized lived experience to more abstract generalizations and principles that both foster conceptual thinking about that lived experience and foster more purposeful and principled future planning and activity.

This could take the form of prompting a teacher to a more abstract decontextualized conceptualization of an element of classroom lived experience during mentoring interaction. Similarly, in assessing and giving feedback on student teachers' written assignments, teacher educators could consciously seek out or offer language that represents a level of decontextualization beyond that of simple narrative. Also, while planning activities, teacher educators could consciously seek out 
language-based activities that promote the use of the language of conceptual thinking, as represented by the taxonomy of conceptualizations.

The construct of conceptual thinking not only allows an expert teacher to deal with the many complexities of the language classroom in a purposeful and effective manner, but as has been suggested, it can serve as a framework for constructing teacher education activities. Awareness of how language can be used to model conceptual thinking for novice teachers, as illustrated by our data, can help teacher educators to be more proactive and purposeful in their attempts to foster conceptual thinking in novice teachers during language teacher education activities. This is especially true of interaction within the POC, with its primary focus on learning from reflection on the lived experience of the classroom. Helping novice teachers consciously develop the ability to think conceptually about classroom events is one step towards helping them become experts in dealing with the complexities of the language classroom.

\section{Notes}

1. The terms everyday and spontaneous are often used interchangeably by scholars writing in the field of SCT (e.g. Bakhust, 2007; Johnson, 2009; Wertsch, 1985) and are used in the same fashion here.

2. We would like to express our gratitude to an anonymous reviewer for pointing out this primary focus.

3. We thank an anonymous reviewer for identifying this distinction.

\section{References}

Bakhurst, D. (2007). Vygotsky's demons. In H. Daniels, M. Cole, \& J. V. Wertsch (Eds.), The Cambridge companion to Vygotsky (pp. 50-76). New York: Cambridge University Press.

Borg, S. (2006). The distinctive characteristics of foreign language teachers. Language Teaching Research, 10, 3-31.

Daniels, H. (2007). Pedagogy. In H. Daniels, M. Cole, \& J. V. Wertsch (Eds.), The Cambridge companion to Vygotsky (pp. 307-332). New York: Cambridge University Press.

Dunn, W. (2011). Working towards social inclusion through concept development in second language teacher education. In K. E. Johnson \& P. R. Golombek
(Eds.), Research on second language teacher education: A sociocultural perspective on professional development (pp. 50-64). New York: Routledge.

Freeman, D. (1991). "To make the tacit explicit": Teacher education, emerging discourse, and the conceptions of teaching. Teaching and Teacher Education, 7(5/6), 439454.

Freeman, D. (1993). Renaming experience/reconstructing practice: Developing new understandings of teaching. Teaching and Teacher Education, 9, 485-497.

Freeman, D. (2002). The hidden side of the work: Teacher knowledge and learning to teach. Language Teaching, $35,1-13$.

Gredler, M. E. (2009) Hiding in plain sight: The stages of mastery/self-regulation in Vygotsky's culturalhistorical theory, Educational Psychologist, 44, 1, 1-19.

Gredler, M. E., \& Shields, C. C. (2008). Vygotsky's legacy: A foundation for research and practice. New York: The Guildford Press.

Harvey, J. K. (2011). A sociocultural-theory-based study of the impact of mediation during postobservation conferences on language teacher learning. (Unpublished doctoral dissertation). University of South Florida, Tampa.

Johnson, K.E. (2009). Second language teacher education: A sociocultural perspective. New York: Routledge.

Johnson, K.E., \& Golombek, P.R. (2011). Research on second language teacher education: A sociocultural perspective on professional development. New York: Routledge.

Mercer, N. (2004). Sociocultural discourse analysis: Analysing classroom talk as a social mode of thinking. Journal of Applied Linguistics, 1(2), 137-168.

Nauman, G. (2011). Synthesizing the academic and the everyday: A Chinese teacher's developing conceptualization of literacy. In K. E. Johnson \& P. R. Golombek (Eds.), Research on second language teacher education: A sociocultural perspective on professional development (pp. 102-117). New York: Routledge.

Shulman, L. (1988). The dangers of dichotomous thinking in education. In P. Grimmet, \& G. Erikson (Eds.), Reflections on teacher education (pp. 31-39). New York: Teachers College Press.

Smagorinsky, P., Cook, L. S., \& Johnson, T. S. (2003). The twisting path of concept development in learning to teach. Teachers College Record, 105, 1399-1436.

Tsui, A. B. M. (2003) Understanding expertise in teaching. Cambridge, UK: Cambridge University Press. 
Vygotsky, L. S. (1986). Thought and language. Cambridge, MA: MIT Press.

Wertsch, J. V. (1985). Vygotsky and the social formation of mind. Cambridge, MA: Harvard University Press.

Recebido em: 05/01/2015

Aceito em: 25/02/2015 